\title{
THROMBOLYTIC TREATMENT OF THROMBOSIS ON THE AORTIC VALVULAR PROSTHESIS COMPLICATED BY BRAIN EMBOLISM
}

\author{
Lucie Horákovál, Radek Pudil', Jan Raupach ${ }^{2}$, Jan Vojáćek ${ }^{1}$ \\ Charles University in Prague, Faculty of Medicine and University Hospital Hradec Králové, Czech Republic: $1^{\text {st }}$ Department \\ of Medicine ${ }^{1}$, Department of Radiology ${ }^{2}$
}

\begin{abstract}
Summary: The authors present a case of thrombosis on the St. Jude Medical 19 aortic valve prosthesis. The diagnosis was confirmed by transthoracic and transoesofageal echocardiography, cardiac fluoroscopy revealed restricted movement of the aortic valve prosthesis leaflet. Thrombolytic therapy was complicated with brain embolism that was successfully percutaneously removed from the cerebral artery by the mechanical device. The patient has fully recovered without any neurological residual symptoms. This case report should be instructive to other clinicians who encounter the same complications after thrombolytic treatment.
\end{abstract}

Key words: Prosthetic heart valve thrombosis; Recombinant tissue plasminogen activator; Brain embolism

\section{Introduction}

Thrombotic occlusion of the mechanical valve prostheses continues to be an uncommon but serious complication. This obstruction is associated with changes in clinical condition, and suspicion of the thrombotic obstruction should be higher if there has been inadequate anticoagulation or a cause for increased coagulability (infection, dehydration, etc.). It requires fast treatment.

Emergency surgery (thrombectomy or valve replacement) is very often associated with high risks because it is reintervention and is performed under acute conditions. On the other hand, thrombolytic treatment carries risks of bleeding, systemic embolism and recurrent embolism (9). We present a case in which we used thrombolytic treatment that was complicated by embolism into the brain and that was successfully treated with immediate endovascular mechanical elimination from the cerebral artery without any neurological handicap.

\section{Case report}

A 55-year old woman underwent aortic valve replacement (bi-leaflet St. Jude Medical 19) because of congenital bicuspid aortic valve disease, which progressed to symptomatic stenosis. Ten days after successful valve replacement surgery the patient was discharged from hospital on warfarin treatment (INR was 2.14). At home, this patient had a cold and 39 days later, the patient was hospitalized for shortness of breath and fatigue. On admission, one patient presented with dyspnoea, orthopnoea and no prosthetic valve clicks. Blood pressure was $120 / 80 \mathrm{~mm} \mathrm{Hg}$, the pulse was $56 / \mathrm{min}$ and regular. The ECG showed sinus rhythm and left axis. The laboratory showed an INR of 1.34.

The transthoracic and transoesofageal echocardiography showed preserved left ventricular function (LVEF $70 \%$ ), vegetation on the aortic valve prosthesis with restricted movement of the leaflet, calculated transvalvular systolic peak (mean gradient of 45-50/25-30 mm Hg) and significant aortic regurgitation (Fig. 1). The fluoroscopy confirmed restriction of the movement of the one aortic valve prosthesis leaflet (Fig. 2). Although this patient was

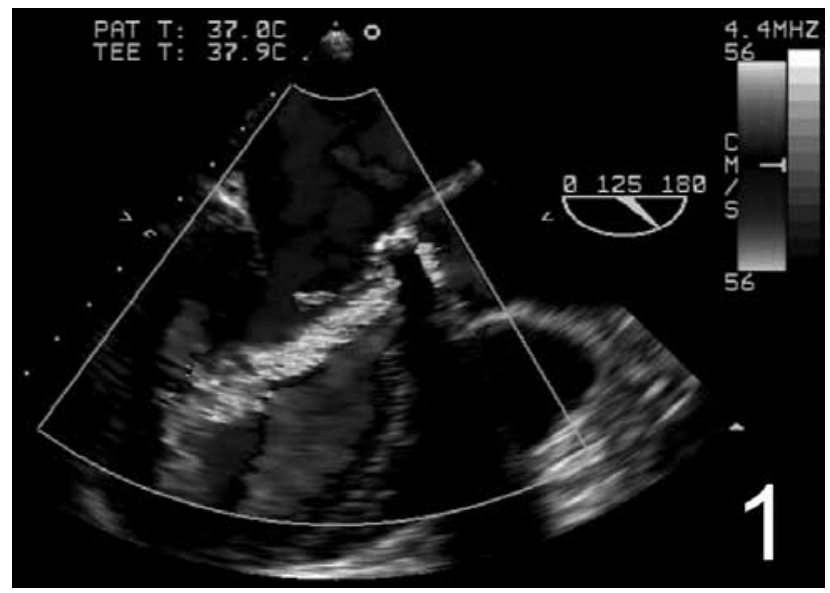

Fig. 1: The echocardiography confirmed vegetation on the aortic valve prosthesis and significant aortic regurgitation. 


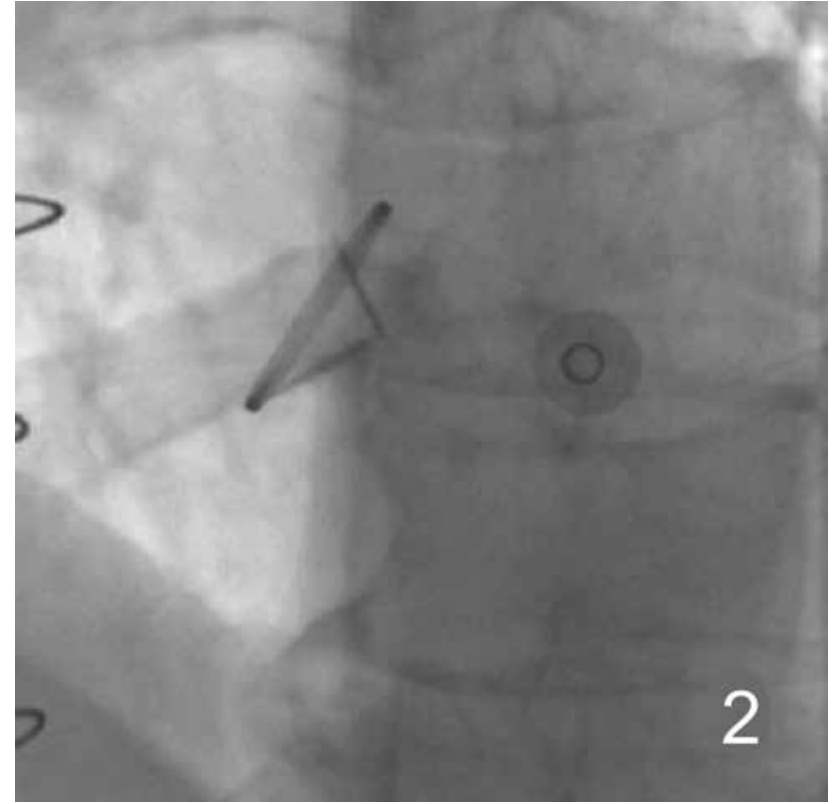

Fig. 2: The fluoroscopy showed restriction of the movement of the one aortic valve prosthesis leaflet.

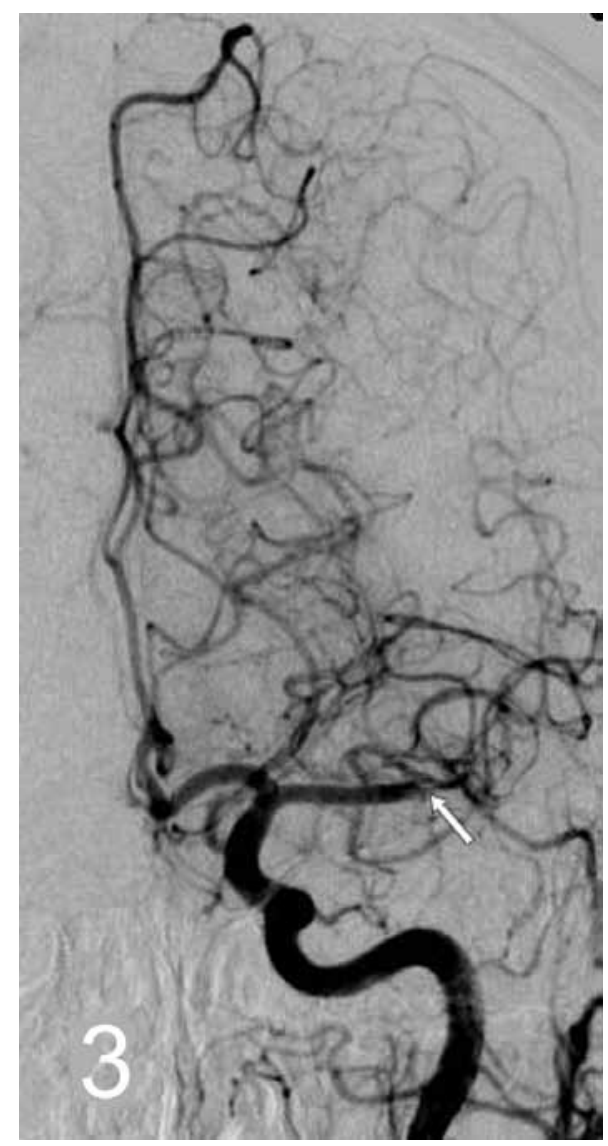

Fig. 3: The contrast angiography confirmed the brain embolism of the left middle cerebral artery in distal M1 segment before bifurcation. acquainted with the risks of surgical and thrombolytic therapy, the patient preferred the thrombolytic treatment.

After short ineffective heparin treatment, thrombolytic therapy was initiated (r-tPA, Actilyse Boehringer Ingelheim). It was re-counted in accordance with the weight of this patient (total dose of r-tPA was $85 \mathrm{mg}$ - an initial bolus of $15 \mathrm{mg}$ followed by $42 \mathrm{mg}$ in 30 minutes and $28 \mathrm{mg}$ in 60 minutes).

Thrombolysis was stopped after 30 minutes due to the advancement of right hemiparesis and expressive aphasia. The contrast CT imaging showed a focus of ischemia in the area supplied by the left middle cerebral artery. The contrast angiography revealed the brain embolism of the left middle cerebral artery in distal M1 segment before bifurcation (Fig. 3). The catheter was led to the obstruction from the right groin and local thrombolysis was applied there. Because this method of recanalisation was unsuccessful, a microcatheter Concentric with accessory equipment Merci (Mechanical Embolus Removal in Cerebral Ischemia, Concentric Medical) was applied for mechanical extraction (10).

Through the microcatheter Concentric with the accessory equipment Merci for mechanical extraction the total

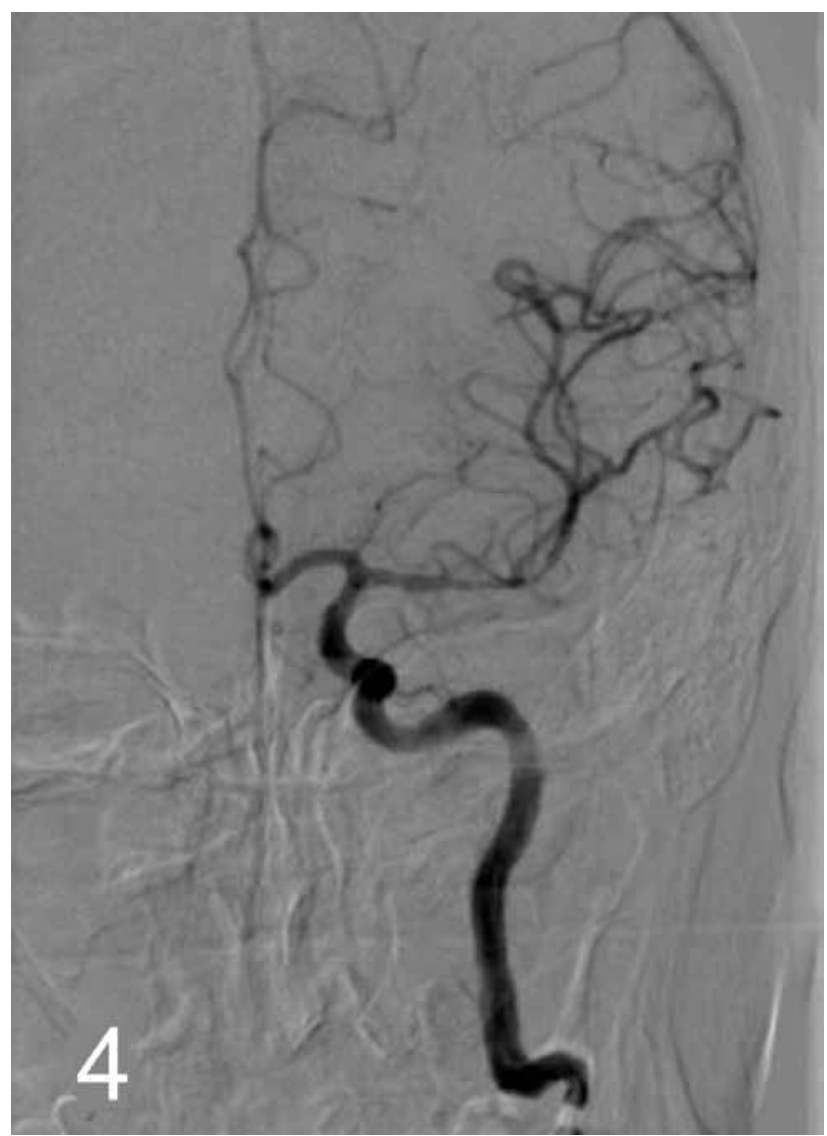

Fig. 4: The total embolic occlusion was converted to the obstruction of the one parietooccipital artery through the microcatheter concentric. 
embolic occlusion was converted to the obstruction of one parietooccipital artery that is supplied to the periphery from the basilar artery (Fig. 4). During this instantaneous treatment the neurological state was rectified. Only slight expressive aphasia outlasted, which disappeared in a few days. After the intravenous thrombolysis, the function of the aortic replacement was renewed.

We heard normal heart sounds without any murmurs and prosthetic valve clicks. The echocardiography confirmed normal movement of the leaves of the aortic prosthesis and the fall of the systolic gradient. The fluoroscopy proved the normalization of the function of the prosthesis - two parallel lines during diastole and apex angle of $120^{\circ}$ during systole. This patient was discharged from the hospital with INR of 2.0 .

\section{Discussion}

Nowadays, mechanical or biological prosthesis, allografts or autografts are implanted. The mechanical prosthesis has an unrestricted lifetime, whereas the biological prosthesis degenerates over time. The cause of the dysfunction of the prosthesis is: thrombotic obstruction, the pannus and the defect of prosthesis or endocarditis on the prosthesis. Thrombotic obstruction on the valve replacement is a very rare but very serious complication with an incidence reported from $0.03 \%$ to $4.3 \%$ per patient yearly (3, $5,7)$. There are a lot of causes that can induce the origin of this occlusion - most frequent is an inadequate anticoagulant therapy, then a history of thromboembolism, hypercoagulable states, mitral valve replacement, left atrial diameter $>50 \mathrm{~mm}, \mathrm{LVEF}<35 \%$, atrial fibrillation, congenital heart anomalies, infection, dehydration, pregnancy and noncompliance with anticoagulant medication $(1,8)$. Various valve prostheses have different thrombogenicity: low risk (Carbomedics in aortic position, St Jude Medical, Medtronic Hall and recommended target INR is 2.5), medium (Bjork-Shiley, other bileaflet valves and optimal target INR is 3.0), high risk (Lillehei-Kaster, Omniscience, StarrEdwards and recommended target INR is 3.5) (9).

For diagnosis, the following are necessary: changes in the clinical state and in the ausculatory findings, transthoracic (TTE) or transoesophageal echocardiography (TEE) and fluoroscopy examinations. Clinical signs, such as orthopnoea, dyspnoea, associated with inaudible clicks of valve prosthesis and with new systolic or diastolic murmurs, may indicate obstruction on the valve prosthesis. This complication is usually noted on admission or follows up TTE, TEE and fluoroscopy. Through these examinations the diagnosis is confirmed (prosthetic valve thrombus is recognized as soft and homogeneous, mobile or fixed echo densities located at the valve occluder, the mitral valve mean gradient is $>10 \mathrm{~mm} \mathrm{Hg}$ or the aortic mean gradient is $>40 \mathrm{~mm} \mathrm{Hg}$ (5), immovable leaf of the valve prosthesis).

There are three possibilities to treat this complication: the surgical treatment, the thrombolytic treatment and the anticoagulant therapy. Surgical treatment is indicated for patients with low perioperative risk, in critically ill patients with obstructive thrombosis without serious comorbidity, in patients with the thrombosis on the mitral or aortic valve, if the thrombus is mobil or if the diameter of the thrombus is higher than $10 \mathrm{~mm}$, if the surgery therapy is available or if there is no effect of the fibrinolysis. Surgical treatment in patients with NYHA III-IV is associated with high risk - the decision between surgical or thrombolytic treatment is individual. Thrombolytic treatment is indicated in patients with the thrombosis on the tricuspidal or pulmonal valve, if the thrombus is smaller than $10 \mathrm{~mm}$ or if the patient prefers the thrombolytic treatment. Because the thrombolytic treatment is associated with high risks of brain embolism, the contrast angiography must be reserved in advance. In that case, where the thrombosis on the mechanical valve replacement is associated with inadequate anticoagulation, heparin is indicated. If there is no effect and the patient has no serious comorbidity, then surgery is necessary. Anticoagulant treatment is used in patients with very small thrombotic obstruction and in the asymptomatic patients.

There are many protocols for thrombolytic treatment Streptokinase infusion of 250000 IU for 30 minutes followed by $100000 \mathrm{IU} / \mathrm{h}$ for a maximum of 72 hours or the dose of $4400 \mathrm{IU} / \mathrm{kg}$ of urokinase for 30 minutes, followed by $4400 \mathrm{IU} / \mathrm{kg} / \mathrm{h}$ (1). Tissue plasminogen activator (r-tPA) has been used in critically ill patients in an accelerated protocol, at an initial bolus of $15 \mathrm{mg}$ followed by $85 \mathrm{mg}$ in 90 minutes (2). A higher embolic complication rate has been reported for r-tPA (4). In this case we decided for r-tPA. There are complications of thrombolytic treatment: peripheral or central embolism in 10-15\%, cardiogenic shock, and risk of rethrombosis in $15 \%$ or death.

This case report shows a complication of thrombolytic treatment - brain embolism - that was successfully removed from the middle cerebral artery by the mechanical extractor without any neurological handicap.

People who undergo valve replacement must be instructed about the oral anticoagulation therapy and about the necessity of regular checking of INR. We must know the states that increased coagulability and that each type of prosthesis has a different thrombogenicity and recquires different target of INR. At this time, we have at our disposal surgery or thrombolytic treatment and the risks and benefits of both treatments should be individualised.

\section{References}

1. Caceres-Loriga F, Peréz-Lopéz J, et al. Thrombolysis as first choice therapy in prosthetic heart valve thrombosis. A study of 68 patients. J Thromb Thrombolysis 2006;21:185-90.

2. DeNofrio D, Ament AF, Mark JB, George SE Accelerated tPA for treatment of prosthetic valve thrombosis. Clin Cardiol 1996;19:665-8.

3. Koller PT, Aron KV Thrombolytic therapy of left side prosthetic valve thrombosis. Chest 1995, 108:1683-9.

4. Lengyel M, Fuster V, Keltai M, et al. Guidelines for management of left-side prosthetic valve thrombosis: a role for thrombolytic therapy. Consensus Conference on prosthetic valve thrombosis. J Am Coll Cardiol 1997;30:1521-6. 
5. O”zkan M., Kaymaz C, Kirma C, et al. Intravenous thrombolytic treatment of mechanical prosthetic valve thrombosis: a study using serial transesophageal echocardiography. J Am Coll Cardiol 2000;35:1881-9.

6. Popelová J, et al. Doporučené postupy pro diagnostiku a léčbu chlopenních srdečních vad v dospělosti. Cor et Vasa 2007:K195-K234.

7. Silber H, Khan SS, Matloff JM, et al: The St. Jude valve: Thrombolysis as the first line therapy for cardiac valve thrombosis. Circulation 1993;87:30-37.
8. Tang G., Rao V., Siu S., Butany J. Thrombosis of mechanical mitral valve prosthesis. Journal of Cardiac Surgery 2005;20:481.

9. Vahanian A, Baumgartner $\mathrm{H}$ et al. Guidelines on the management of valvular heart disease. European Heart Journal 2007;28:230-68.

10. Wade S. Smith et al. Safety and efficacy of mechanical embolectomy in acute ischemic stroke: Results of the MERCI trial. Stroke 2005;36:1432-8.

\section{Corresponding author:}

MUDr. Lucie Horáková, University Hospital in Hradec Králové, $1^{\text {st }}$ Department of Medicine, Sokolská 581, 50005 Hradec Králové, Czech Republic, e-mail: lucka.horakova@email.cz 